OPEN ACCESS

Edited by:

Maik Gollasch,

Charité University Medicine, Germany

Reviewed by:

Zsolt Bagi,

Georgia Regents University, USA

Ningjun $L i$,

Virginia Commonwealth University,

USA

${ }^{*}$ Correspondence:

Timothy R. Nurkiewicz

tnurkiewicz@hsc.wvu.edu

Specialty section:

This article was submitted to

Vascular Physiology,

a section of the journal

Frontiers in Physiology

Received: 21 August 2015 Accepted: 02 November 2015 Published: 17 November 2015

Citation:

Minarchick VC, Stapleton PA,

Sabolsky EM and Nurkiewicz TR (2015) Cerium Dioxide Nanoparticle

Exposure Improves Microvascular

Dysfunction and Reduces Oxidative

Stress in Spontaneously Hypertensive

Rats. Front. Physiol. 6:339

doi: 10.3389/fphys.2015.00339

\section{Cerium Dioxide Nanoparticle Exposure Improves Microvascular Dysfunction and Reduces Oxidative Stress in Spontaneously Hypertensive Rats}

\author{
Valerie C. Minarchick ${ }^{1,2}$, Phoebe A. Stapleton ${ }^{1,2}$, Edward M. Sabolsky ${ }^{3}$ and \\ Timothy R. Nurkiewicz ${ }^{1,2 *}$ \\ ${ }^{1}$ Center for Cardiovascular and Respiratory Sciences, West Virginia University School of Medicine, Morgantown, WV, USA, \\ ${ }^{2}$ Department of Physiology and Pharmacology, West Virginia University School of Medicine, Morgantown, WV, USA, \\ ${ }^{3}$ Department of Mechanical and Aerospace Engineering, West Virginia University, Morgantown, WV, USA
}

The elevated production of reactive oxygen species (ROS) in the vascular wall is associated with cardiovascular diseases such as hypertension. This increase in oxidative stress contributes to various mechanisms of vascular dysfunction, such as decreased nitric oxide bioavailability. Therefore, anti-oxidants are being researched to decrease the high levels of ROS, which could improve the microvascular dysfunction associated with various cardiovascular diseases. From a therapeutic perspective, cerium dioxide nanoparticles $\left(\mathrm{CeO}_{2} \mathrm{NP}\right)$ hold great anti-oxidant potential, but their in vivo activity is unclear. Due to this potential anti-oxidant action, we hypothesize that injected $\mathrm{CeO}_{2}$ NP would decrease microvascular dysfunction and oxidative stress associated with hypertension. In order to simulate a therapeutic application, spontaneously hypertensive $(\mathrm{SH})$ and Wistar-Kyoto (WKY) rats were intravenously injected with either saline or $\mathrm{CeO}_{2} \mathrm{NP}(100 \mu \mathrm{g}$ suspended in saline). Twenty-four hours post-exposure mesenteric arteriolar reactivity was assessed via intravital microscopy. Endothelium-dependent and -independent function was assessed via acetylcholine and sodium nitroprusside. Microvascular oxidative stress was analyzed using fluorescent staining in isolated mesenteric arterioles. Finally, systemic inflammation was examined using a multiplex analysis and venular leukocyte flux was counted. Endothelium-dependent dilation was significantly decreased in the $\mathrm{SH}$ rats (29.68 $\pm 3.28 \%$, maximal response) and this microvascular dysfunction was significantly improved following $\mathrm{CeO}_{2} \mathrm{NP}$ exposure (43.76 $\pm 4.33 \%$, maximal response). There was also an increase in oxidative stress in the $\mathrm{SH}$ rats, which was abolished following $\mathrm{CeO}_{2} \mathrm{NP}$ treatment. These results provided evidence that $\mathrm{CeO}_{2} \mathrm{NP}$ act as an anti-oxidant in vivo. There were also changes in the inflammatory profile in the WKY and SH rats. In WKY rats, IL-10 and TNF- $\alpha$ were increased following $\mathrm{CeO}_{2} \mathrm{NP}$ treatment. Finally, leukocyte flux was increased in the $\mathrm{SH}$ rats (34 \pm 4 vs. $17 \pm 3$ cells/min in the normotensive controls), but this activation was decreased following exposure (15 \pm 2 vs. $34 \pm 4$ cells/min). These results indicated that $\mathrm{CeO}_{2} \mathrm{NP}$ may alter the inflammatory response in both $\mathrm{SH}$ and WKY rats. Taken together, these results provide evidence that $\mathrm{CeO}_{2} \mathrm{NP}$ act as an anti-oxidant in vivo and may improve microvascular reactivity in a model of hypertension.

Keywords: microcirculation, cerium dioxide nanoparticles, hypertension, reactive oxygen species, anti-oxidant 


\section{INTRODUCTION}

There is a growing interest in developing therapeutic interventions that result in more precise and individualized treatment. Engineered nanomaterials (ENM) are prime candidates for therapeutic applications for several reasons (Kelkar and Reineke, 2011). First, the size of ENM ( $\leq 100 \mathrm{~nm}$ in at least one dimension) creates a large surface area for the attachment of various pharmaceuticals and/or imaging agents (Borm et al., 2006). Their small size also allows ENM to access every bodily component via the circulation (Stapleton and Nurkiewicz, 2014). Secondly, by altering the surface chemistry and/or using specific ENM, they may be precisely aimed at target areas in the body, which (in conjunction with a high surface) reduces the dosage needed to treat certain pathologies (Roco et al., 2010; Yu et al., 2010a). Finally, many ENM possess inherent unique characteristics (e.g., auto-fluorescence, and anti-oxidant activity) that can be exploited to increase their pharmaceutical relevance (Borm et al., 2006).

Cerium dioxide nanoparticles $\left(\mathrm{CeO}_{2} \mathrm{NP}\right)$ are one type of ENM that are currently being investigated for their possible therapeutic significance (Colon et al., 2009; Kim et al., 2012; Madero-Visbal et al., 2012). $\mathrm{CeO}_{2}$ NP have catalytic activity, which arises from the presence of two valence states $\left(\mathrm{Ce}^{3+}\right.$ and $\mathrm{Ce}^{4+}$ ) (Celardo et al., 2011). Due to the oxygen vacancies present in these nanoparticles, they are able to react with surrounding reactive oxygen species (ROS), thus introducing $\mathrm{CeO}_{2} \mathrm{NP}$ as a potential in vivo mimetic for endogenous anti-oxidants like superoxide dismutase (Heckert et al., 2008; Xu and Qu, 2014; Dunnick et al., 2015).

Like many pharmaceuticals, $\mathrm{CeO}_{2} \mathrm{NP}$ research has produced conflicting results about the efficiency of its potential antioxidant activity. In vitro analysis has shown an increase in ROS generation and inflammation following $\mathrm{CeO}_{2} \mathrm{NP}$ co-incubation; however, other studies with cardiac progenitor and endothelial cells have shown a decrease in both these parameters (Park et al., 2008; Gojova et al., 2009; Horie et al., 2011; Wingard et al., 2011; Pagliari et al., 2012). The in vivo analysis of these nanoparticles is even more complex. Experimentally, injected $\mathrm{CeO}_{2} \mathrm{NP}$ have been shown to decrease tissue damage, which is commonly associated with radiation treatments and strokes (Colon et al., 2009; Kim et al., 2012). Despite these promising results, $\mathrm{CeO}_{2} \mathrm{NP}$ injected into young healthy rats may have detrimental effects that result in microvascular dysfunction (Minarchick et al., 2015). Currently, it is unclear if the potential positive effects of $\mathrm{CeO}_{2} \mathrm{NP}$ are pathology specific. Furthermore, it is also unknown how $\mathrm{CeO}_{2}$ NP specific alterations in ROS production affect microvascular function.

Hypertension affects one out of three Americans and is a leading factor in the development of cardiovascular disease (Nwankwo et al., 2013). This pathology is associated with microvascular dysfunction that is, at least partially, attributed to increased ROS generation due to chronic inflammation, mitochondrial dysfunction, and/or nitric oxide synthase (NOS) uncoupling (Félétou and Vanhoutte, 2006; Brito et al., 2015). In addition to decreasing vasoactive factors directly, the elevated levels of ROS are capable of increasing steroid hormone production, which can impair NOS activity and prostaglandin formation, which increase the risk of organ damage (Suzuki et al., 1995). The influence of ROS on microvascular function has led to the investigation of anti-oxidants as potential therapeutic treatments (Brito et al., 2015). If the anti-oxidant potential of $\mathrm{CeO}_{2} \mathrm{NP}$ were better understood, this ENM could be developed as a treatment to decrease high levels of ROS, which may ultimately reduce the microvascular dysfunction associated with various diseases such as hypertension.

Therefore, the purpose of this study was to assess the in vivo anti-oxidant potential of $\mathrm{CeO}_{2} \mathrm{NP}$ in a high $\mathrm{ROS}$ environment, specifically hypertension. Previous in vitro studies have shown that in the presence of elevated $\mathrm{ROS} \mathrm{CeO}_{2} \mathrm{NP}$ act as an antioxidant and can decrease ROS (Minarchick et al., 2015). Based on these results, we hypothesize that following injection $\mathrm{CeO}_{2}$ $\mathrm{NP}$ will act as an anti-oxidant and reduce the oxidative stress and microvascular dysfunction that is associated with hypertension. This potential outcome may provide valuable information about the anti-oxidant activity of $\mathrm{CeO}_{2} \mathrm{NP}$, which is pivotal for it to be developed as an anti-oxidant treatment for cardiovascular diseases.

\section{METHODS AND MATERIALS}

\section{Cerium Dioxide Nanoparticle $\left(\mathrm{CeO}_{2} \mathrm{NP}\right)$ Production and Characterization}

$\mathrm{CeO}_{2} \mathrm{NP}$ powders were synthesized by a hydrothermal process as previously described (Minarchick et al., 2013). Briefly, cerium (IV) ammonium nitrate (99+\% Alfa Aesar, Ward Hill, MA) was added to de-ionized water $\left(\mathrm{H}_{2} \mathrm{O}\right)$ and this solution was added drop-wise into a basic solution of tetramethylammonium hydroxide pentahydrate and de-ionized $\mathrm{H}_{2} \mathrm{O}$. The $\mathrm{pH}$ of the dispersion was altered to $\sim 10.5$ with ammonium hydroxide and was maintained throughout the reaction. The dispersion was placed in a $300 \mathrm{ml}$ Autoclave Engineers EZE-Seal autoclave (Erie, PA) at $240^{\circ} \mathrm{C}$ for $1 \mathrm{~h}$. Once removed from the autoclave, the dispersion was placed into a centrifuge and the liquid was removed and replaced with ethanol. After the washing step, the dispersion was dried at $60^{\circ} \mathrm{C}$ overnight and sieved through a 200 mesh screen for characterization. The nanoparticles were previous characterized (Minarchick et al., 2013). Briefly, the $\mathrm{CeO}_{2}$ NP had a surface area of $81.36 \mathrm{~m}^{2} / \mathrm{g}$ measured by Micromeritics ASAP 2020 (Norocross, GA). JEOL JEM2100 High Resolution Transmission Electron Microscope (TEM) (Peabody, MA) determined the primary particle size $(\sim 2-$ $4 \mathrm{~nm}$ ) and shape (spherical). The average agglomerate size in saline (Normosol, Nospira Inc., Lake Forest, IL) and 5\% fetal bovine serum (FBS) was $191 \mathrm{~nm}$ as determined by dynamic light scattering via a Malvern Zetasizer version 7.01 (Westborough, $\mathrm{MA}$ ). Finally, the valence state of the $\mathrm{CeO}_{2} \mathrm{NP}$ was $\sim 81 \% \mathrm{Ce}^{4+}$ and $\sim 19 \% \mathrm{Ce}^{3+}$ determined by $\mathrm{x}$-ray photoelectron spectroscopy (PHI 5000 Versaprobe XPS, Chanhassen, MN).

\section{Experimental Animals}

Male spontaneously hypertensive (SH) rats and Wistar-Kyoto (WKY) rats ( $\sim 10$ weeks old) were purchased from Harlan 
laboratories (Indianapolis, IN). SH rats were studied because they are a well-established model of microvascular dysfunction and excess local ROS production (Bakker et al., 2014; Brito et al., 2015). WKY rats were used as a normotensive control for the SH in these experiments (Okamoto et al., 1967). The rats were housed at the West Virginia University (WVU) Health Sciences Center Vivarium, in laminar flow cages, under controlled humidity and temperature, with a $12 \mathrm{~h}$ light/dark cycle, and food and water were provided ad libitum. The animals were acclimated for a minimum of 2 days prior to use. The WVU Institutional Animal Care and Use Committee at WVU approved all procedures.

\section{$\mathrm{CeO}_{2}$ NP Solution Preparation and Exposure}

The animals used in these studies were injected with a $100 \mu \mathrm{g}$ dose $(\sim 0.42 \mathrm{mg} / \mathrm{kg})$ of $\mathrm{CeO}_{2} \mathrm{NP} 24 \mathrm{~h}$ prior to experimental assessments. To prepare this dose, a stock suspension was prepared daily containing $1.1 \mathrm{mg}$ of dry $\mathrm{CeO}_{2} \mathrm{NP}$ powder and $10 \mathrm{ml}$ of Normosol with $5 \%$ FBS to reduce agglomeration (Minarchick et al., 2013, 2015). The $\mathrm{CeO}_{2} \mathrm{NP}$ were vortexed for $5 \mathrm{~min}$ and then sonicated on ice for an additional $5 \mathrm{~min}$. Rats were lightly anesthetized with isoflurane gas (5\% induction, $2-3.5 \%$ maintenance). Rats were divided into four groups and were intravenously injected in the tail vein with a $900 \mu \mathrm{l}$ bolus dose of saline (WKY-Sham, SH-Sham) or $\mathrm{CeO}_{2} \mathrm{NP}$ stock suspension (WKY-CeO ${ }_{2} \mathrm{NP}, \mathrm{SH}-\mathrm{CeO}_{2} \mathrm{NP}$ ) using a $23 \mathrm{G}$ needle. The final dose was $100 \mu \mathrm{g}$ per rat. This dose was predetermined to cause a $50 \%$ impairment in microvascular function in previous experiments and was also within the functional dose range for $\mathrm{CeO}_{2}$ NP (Kim et al., 2012; Minarchick et al., 2015)Rats were monitored after treatment until they regained consciousness.

\section{Intravital Microscopy Preparation}

Animals were anesthetized with Inactin $[100 \mathrm{mg} / \mathrm{kg}$, intraperitoneal (ip) injection] and placed on a heating pad to maintain a $37^{\circ} \mathrm{C}$ rectal temperature. The trachea was intubated to maintain a patent airway, and the right carotid artery was cannulated to monitor mean arterial pressure (MAP) and heart rate. A loop of the small intestine (ileum) was surgically exteriorized. Once exteriorized, two small incisions $6-10 \mathrm{~cm}$ apart were made along the intestinal wall using thermal cautery and the chyme was flushed from the lumen through the incisions. The ileum was then carefully placed over a clear pedestal, and gently secured so that the mesenteric circulation was at its in situ length. Throughout the preparation and experiment, the exposed mesentery was continuously superfused with an electrolyte solution $\left(119 \mathrm{mM} \mathrm{NaCl}, 25 \mathrm{mM} \mathrm{NaHCO}_{3}, 6 \mathrm{mM} \mathrm{KCl}\right.$, and $3.6 \mathrm{mM} \mathrm{CaCl}_{2}$ ) that was warmed to $37^{\circ} \mathrm{C}$ and equilibrated with $95 \% \mathrm{~N}$ and $2-5 \% \mathrm{CO}_{2}$ (pH 7.35-7.40). Intestinal motility was suppressed using isoproterenol hydrochloride $(10 \mathrm{mg} / \mathrm{l}$, Sigma-Aldrich, St. Louis MO) and phenytoin (20 mg/l, SigmaAldrich, St. Louis MO). At these concentrations, isoproterenol and phenytoin have no significant effect on arteriolar tone (Bohlen et al., 1978). The superfusate rate was maintained at 4-6 $\mathrm{ml} / \mathrm{min}$ to minimize equilibration with atmospheric oxygen (Boegehold and Bohlen, 1988). The animal preparation was then transferred to the stage of an intravital microscope coupled to a charge-coupled device (CCD) video camera. Observations were made with a $20 \mathrm{x}$ water immersion objective. Video images were displayed on a high-resolution color video monitor and recorded for off-line analysis. During analysis, arteriolar inner diameters were measured with a video caliper and one to three arterioles were studied per rat.

\section{Microvascular Analysis}

Arteriolar endothelium-dependent dilation was evaluated using acetylcholine (ACh, $0.25 \mathrm{M}$ ). ACh was iontophoretically applied to individual 5th order arterioles $(20,100$, and $150 \mathrm{nA})$. Glass micropipettes were beveled at a $23-25^{\circ}$ angle with $2-4 \mu \mathrm{m}$ inner diameter tip and filled with ACh (Nurkiewicz et al., 2004). The pipette tip was placed in light contact with the arteriolar wall and a current programmer (Model 260; World Precision Instruments, New Haven, CT) was used to deliver continuous ejection currents $(2 \mathrm{~min}$ ). A recovery period (at least $2 \mathrm{~min}$ ) followed each application. The ACh response determination was repeated in the presence of several chemical interventions which were applied via syringe pump $(0.4 \mathrm{ml} / \mathrm{min})$ into the superfusate delivery line for $30 \mathrm{~min}$. The mesenteric loop was incubated with $\mathrm{N}^{\mathrm{G}}$ monomethyl-L-arginine (L-NMMA, $10^{-4} \mathrm{M}$ ), a NOS inhibitor, to assess the influence of NO. Incubation with indomethacin (INDO, $10^{-5} \mathrm{M}$ ), a cyclooxygenase (COX) inhibitor, was used to assess the influence of COX products. The mesentery was also incubated with 2,2,6,6-tetramethylpiperidine- $\mathrm{N}$-oxyl (TEMPOL, $10^{-4} \mathrm{M}$ ), a superoxide dismutase mimetic, and catalase (50 units $/ \mathrm{ml}$ ), a hydrogen peroxide scavenger, to assess the influence of ROS. All four chemical interventions (L-NMMA, INDO, TEMPOL, and catalase) were applied to the mesentery to determine influence of NO, COX products, and ROS simultaneously. Vascular smooth muscle responsiveness to NO was assessed using sodium nitroprusside (SNP, 0.05 M). SNP was iontophoretically applied to arterioles as previously described (10, 50, and $150 \mathrm{nA})$ (Nurkiewicz et al., 2004). Microvascular reactivity assessments and ejection currents were randomized and two to three assessments were completed per rat. At the end of each experiment, adenosine (ADO, $10^{-4} \mathrm{M}$ ) was added to the superfusate via syringe pump to determine the passive diameter of each arteriole studied.

Finally, leukocyte flux was assessed in mesenteric paired venules to quantify potential microvascular inflammation. Leukocytes that were either stationary or moving but maintained consistent contact with the venular wall for at least $200 \mu \mathrm{m}$ were counted for $1 \mathrm{~min}$ in each venule studied.

\section{Oxidative Stress Analysis}

A separate subset of animals ( $\sim 10$ weeks old) was used to determine changes in microvascular oxidative stress via fluorescent analysis. SH and WKY rats were exposed to either saline or $\mathrm{CeO}_{2} \mathrm{NP}$ as previously described. Twentyfour hour post-exposure, the animals were anesthetized with Inactin $(100 \mathrm{mg} / \mathrm{kg}$, ip injection) and were placed on a heating pad to maintain a $37^{\circ} \mathrm{C}$ rectal temperature. The right carotid artery was cannulated to acquire blood for subsequent cytokine analysis (see Section Pro-inflammatory Cytokine Analysis). The 
mesentery was removed and placed in a dissecting dish with physiological salt solution (PSS) maintained at $4{ }^{\circ} \mathrm{C}$ (Minarchick et al., 2015). Mesenteric arterioles (4th and 5th order) were isolated, transferred to a vessel chamber, cannulated between two glass pipettes, and tied with silk sutures (Living Systems Instrumentation, Burlington, VT). In the absence of light, dihydroethidium (DHE, $10^{-4} \mathrm{M}$ ) was intraluminally infused for $20 \mathrm{~min}$ followed by a $20 \mathrm{~min}$ wash with PSS to remove excess DHE. Prior to imaging, the arterioles were pressurized to $80 \mathrm{~mm}$ $\mathrm{Hg}$ using a servo control system (Sun et al., 1992). The vessel chamber was placed on an Olympus BX51WI upright microscope for imaging. The arteriole was first imaged briefly under traditional bright field settings. The arteriole was illuminated with a mercury lamp for $1 \mathrm{~s}$ with the appropriate excitation and emission filters for detection of ethidium bromide fluorescence (480-550 $\mathrm{nm}$ bandpass, $590 \mathrm{~nm}$ barrier) and hydroethidine fluorescence (330-385 $\mathrm{nm}$ bandpass, $590 \mathrm{~nm}$ barrier). DHE was used because it easily permeates cell membranes and can be oxidized by ROS to form ethidium bromide which intercalates into nuclear DNA (Morgan et al., 1979; Benov et al., 1998).

ROS-associated fluorescence was quantified in the arteriolar wall. A user-defined region of interest (ROI) box $(10 \times 100 \mu \mathrm{m})$ was placed vertically on the endothelial cell layer of the bright field image. It was previously determined that the mesenteric arteriolar wall thickness was $\sim 13 \mu \mathrm{m}$; therefore, the ROI box encompassed the entire endothelial cell layer and most of the vascular smooth muscle layer. The images were analyzed using open access imaging software (ImageJ). The hydroethidine image represented background and non-specific fluorescence, therefore in order to analyze only fluorescence which had been intercalated into the DNA this fluorescence was removed from the ethidium bromide image. The ROI was superimposed on the resulting image in order to acquire the mean fluorescence of the arteriole. Total fluorescence intensity was calculated as average fluorescence intensity per pixel x surface area.

\section{Pro-inflammatory Cytokine Analysis}

The blood collected from the SH and WKY rats was centrifuged $(1100 \times \mathrm{g})$ to separate the blood components. The plasma was collected, flash frozen in liquid nitrogen, and stored in a $-80^{\circ} \mathrm{C}$ freezer until analysis. A pro-inflammatory cytokine multi-spot assay was completed per manufacturer's directions (MesoScale Diagnostics, Rockville, MD). The pro-inflammatory cytokines assessed were: interferon gamma (IFN- $\gamma$ ), interleukins1 beta, 4, 5, 6, 10 and 13 (IL-1 $\beta$, IL-4, IL-5, IL-6, IL-10, and IL-13), tumor necrosis factor alpha (TNF- $\alpha$ ) and keratinocyte chemoattractant/human growth-regulated oncogene (KC/GRO).

Equations: Basal tone was calculated by the following equation,

$$
\text { Basal Tone }(\%)=\left[\left(\mathrm{D}_{\mathrm{M}}-\mathrm{D}_{\mathrm{BD}}\right) / \mathrm{D}_{\mathrm{M}}\right] \times 100
$$

where $\mathrm{D}_{\mathrm{BD}}$ is the baseline diameter measured prior to any current application, and $\mathrm{D}_{M}$ is the passive diameter recorded in the presence of ADO. The experimental responses to ACh and SNP are expressed using the following equation:

$$
\begin{aligned}
& \text { Diameter (Percent Maximal Response })= \\
& \left.\qquad\left[\mathrm{D}_{\mathrm{SS}}-\mathrm{D}_{\mathrm{BD}}\right) /\left(\mathrm{D}_{\mathrm{M}}-\mathrm{D}_{\mathrm{BD}}\right)\right] \times 100,
\end{aligned}
$$

where $D_{S S}$ is the maximal diameter recorded at each current.

\section{Statistics}

Data are expressed as means \pm standard error (SE). Pointto-point differences in the dose-response determinations were evaluated using Two-Way repeated measures analysis of variance (ANOVA) with a Student-Newman-Keuls post-hoc analysis when significance was found. Statistical differences in the slopes of the dose-response determinations were determined by linear regression analysis. The animal characteristics, arteriole characteristics, oxidative stress, and pro-inflammatory cytokine results were analyzed using an One-Way ANOVA with a StudentNewman-Keuls post-hoc analysis when significance was found. All statistical analysis was completed with SigmaPlot 11.0 (San Jose, CA) and GraphPad Prism 5 (San Diego, CA). Significance was set at $p \leq 0.05, \mathrm{n}$ is the number of arterioles, and $\mathrm{N}$ is the number of animals.

\section{RESULTS}

\section{Animal and Arteriolar Characteristics}

There were no significant changes in age or heart rate between the four groups (Table 1). MAP and heart weight were significantly increased in the $\mathrm{SH}$-Sham and $\mathrm{SH}-\mathrm{CeO}_{2} \mathrm{NP}$ groups compared to the normotensive WKY groups (Table 1). These findings are consistent with $\mathrm{SH}$ rat characteristics. There was also a significant increase in body weight in the $\mathrm{SH}-\mathrm{CeO}_{2} \mathrm{NP}$ group compared to the WKY groups (Table 1). Finally, there were no observed differences in starting arteriolar diameter, maximal diameter, or basal tone between the four groups (Table 2). These results indicate that $\mathrm{CeO}_{2} \mathrm{NP}$ injection exposure does not influence blood pressure or arteriolar tone, when comparing the WKY and SH groups.

\section{Endothelium-dependent Dilation}

Endothelium-dependent dilation was significantly impaired in the SH-Sham group (29.68 $\pm 3.28 \%$, maximal response) compared to the WKY groups (53.92 $\pm 4.22 \%$ ) (Figure 1). Following the $100 \mu \mathrm{g}$ injection of $\mathrm{CeO}_{2} \mathrm{NP}$, there was a significant augmentation in endothelium-dependent dilation in the $\mathrm{SH}-\mathrm{CeO}_{2} \mathrm{NP}(43.76 \pm 4.33 \%)$ compared to the SH-Sham group (29.68 $\pm 3.28 \%$ ) (Figure 1). However, this dilation was still significantly impaired compared to the WKY-Sham group $(53.92 \pm 4.22 \%)$ (Figure 1). This data provides evidence that the injected $\mathrm{CeO}_{2} \mathrm{NP}$ partially improve the microvascular dysfunction associated with hypertension.

\section{Endothelium-independent Dilation}

Endothelium-independent dilation was not impaired in the $\mathrm{SH}$ or WKY groups (Figure 2). This indicates that $\mathrm{CeO}_{2} \mathrm{NP}$ injection exposure and hypertension, either alone or together, do not impair arteriolar vascular NO smooth muscle sensitivity. 
TABLE 1 | Animal characteristics.

\begin{tabular}{|c|c|c|c|c|c|c|}
\hline Group & $N$ & Age (wks) & Weight (g) & Heart weight (g) & MAP (mm Hg) & Heart rate (beats/min) \\
\hline WKY-Sham & 22 & $10.48 \pm 0.30$ & $230.5 \pm 5.99$ & $0.97 \pm 0.03$ & $66.25 \pm 2.33$ & $446.20 \pm 25.03$ \\
\hline $\mathrm{WKY}-\mathrm{CeO}_{2} \mathrm{NP}$ & 19 & $10.42 \pm 0.18$ & $226.7 \pm 3.73$ & $0.93 \pm 0.02$ & $69.29 \pm 2.23$ & $471.24 \pm 7.21$ \\
\hline SH-Sham & 24 & $10.08 \pm 0.32$ & $245.7 \pm 6.20$ & $1.12 \pm 0.03^{\star \dagger}$ & $113.33 \pm 5.37^{\star \dagger}$ & $427.83 \pm 18.49$ \\
\hline $\mathrm{SH}-\mathrm{CeO}_{2} \mathrm{NP}$ & 24 & $10.17 \pm 0.33$ & $253.0 \pm 5.41^{\star \dagger}$ & $1.14 \pm 0.04^{* \dagger}$ & $106.66 \pm 5.27^{\star \dagger}$ & $494.37 \pm 12.69$ \\
\hline
\end{tabular}

Values are means $\pm S E ; N$, number of animals; MAP, mean arterial pressure.

${ }^{*} p \leq 0.05$ vs. WKY-Sham; ${ }^{\dagger} p \leq 0.05$ vs. WKY-CeO 2 NP.

TABLE 2 | Arteriole characteristics.

\begin{tabular}{lcccc}
\hline Group & $\boldsymbol{N}$ & $\begin{array}{c}\text { Starting } \\
\text { diameter }(\boldsymbol{\mu} \mathbf{m})\end{array}$ & $\begin{array}{c}\text { Maximal } \\
\text { diameter }(\mu \mathrm{m})\end{array}$ & $\begin{array}{c}\text { Basal } \\
\text { tone (\%) }\end{array}$ \\
\hline WKY-Sham & 42 & $59.35 \pm 2.67$ & $88.00 \pm 3.40$ & $32.75 \pm 1.25$ \\
WKY-CeO 2 NP & 40 & $59.04 \pm 2.65$ & $92.60 \pm 3.65$ & $35.42 \pm 1.53$ \\
SH-Sham & 58 & $57.44 \pm 2.30$ & $85.81 \pm 3.18$ & $32.82 \pm 1.16$ \\
SH-CeO 2 NP & 50 & $60.21 \pm 2.65$ & $96.80 \pm 4.08$ & $37.02 \pm 1.49$
\end{tabular}

Values are means $\pm S E ; n$, number of arterioles.

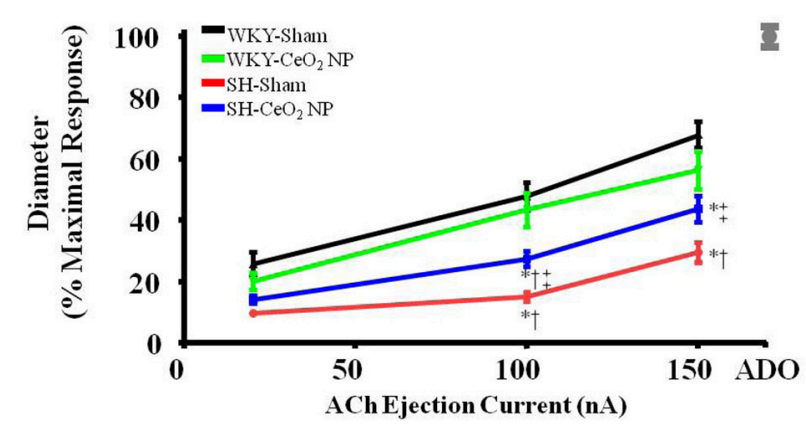

FIGURE 1 | ACh-induced vasodilation was impaired in arterioles from SH-Sham animals but was significantly improved in the $\mathrm{SH}-\mathrm{CeO}_{2} \mathrm{NP}$ group compared to the SH-Sham $(n=12-29)$. The gray mark represents the maximal dilation observed during incubation with ADO at the end of the experiment. ${ }^{*} p \leq 0.05$ vs. WKY-Sham, ${ }^{\dagger} p \leq 0.05$ vs. WKY-CeO 2 NP, $\ddagger_{p} \leq 0.05$ vs. SH-Sham.

\section{Contribution of NO, COX products, and ROS to ACh-induced Vasodilation}

The role of $\mathrm{NO}$ in ACh-induced vasodilation was assessed during incubation with L-NMMA. Incubation of the mesentery with L-NMMA significantly reduced vasodilation in response to ACh, both in terms of the overall slopes and at the highest ejection current, in the WKY-Sham and $\mathrm{WKY}-\mathrm{CeO}_{2} \mathrm{NP}$ groups $(53.92 \pm 4.22 \%$, and $56 \pm 6.13 \%$, respectively vs. $11.86 \pm$ $9.89 \%$, and $25.81 \pm 5.08 \%$ during incubation) (Figures 3A, 4A). Additionally, there was a significant improvement in dilation in the SH-Sham during incubation with L-NMMA (29.68 \pm $3.28 \%$ vs. $50.18 \pm 8.09 \%$ during incubation), but there was no improvement in arteriolar dilation during incubation in the $\mathrm{SH}-\mathrm{CeO}_{2} \mathrm{NP}$ group (Figure 4A).

The role of COX products were assessed during incubation with INDO. There was also a significant impairment in

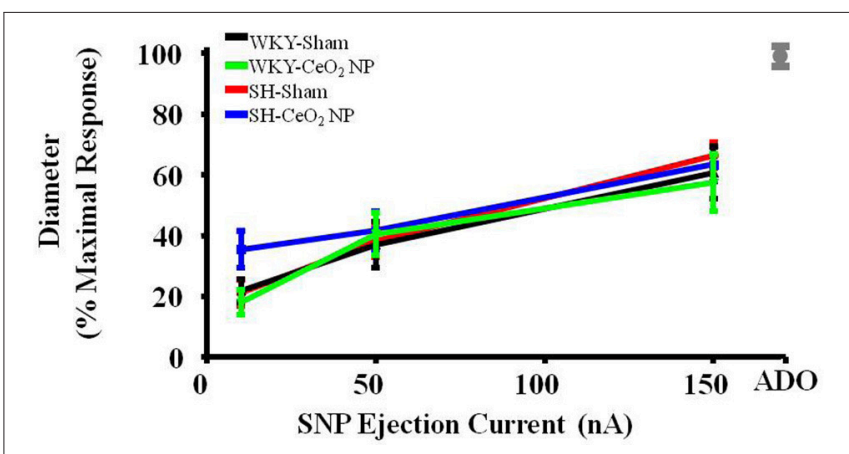

FIGURE 2 | Vascular smooth muscle responsiveness to NO was not impaired in the Sham groups or following $\mathrm{CeO}_{2}$ NP exposure $\left(\mathbf{W K Y}-\mathrm{CeO}_{2} \mathrm{NP}\right.$ and $\mathrm{SH}-\mathrm{CeO}_{2} \mathrm{NP}$ groups; $\left.\boldsymbol{n}=\mathbf{9 - 1 9}\right)$. The gray mark represents the maximal dilation observed during incubation with $\mathrm{ADO}$ at the end of the experiment.

arteriolar reactivity, in regards to the overall slopes and at the highest ejection current, during incubation with INDO in the WKY-Sham and $\mathrm{WKY}-\mathrm{CeO}_{2} \mathrm{NP}$ groups (53.92 \pm $4.22 \%$, and $56 \pm 6.13 \%$, respectively vs. $27.06 \pm 4.84 \%$, and $13.12 \pm 4.28 \%$ during incubation) (Figures 3B, 4B). There was no change in vasodilation during INDO incubation in the $\mathrm{SH}$-Sham group (Figure 4B). Finally, there was a significant increase in vasodilation in the $\mathrm{SH}-\mathrm{CeO}_{2} \mathrm{NP}$ during INDO incubation ( $43.76 \pm 4.33 \%$ vs. $70.73 \pm 7.92 \%$ during incubation) (Figure 4B).

Local ROS was scavenged during simultaneous incubation with TEMPOL and catalase. There was no change in arteriolar vasodilation during TEMPOL and catalase incubation in the WKY-Sham, WKY-CeO $2 \mathrm{NP}$, and $\mathrm{SH}-\mathrm{CeO}_{2} \mathrm{NP}$ groups (Figures 3C, 4C). There was a significant increase in the response to $\mathrm{ACh}$ in the $\mathrm{SH}$-Sham group during incubation with these exogenous anti-oxidants (29.68 $\pm 3.28 \%$ vs. $49.62 \pm 7.86 \%$ during incubation) (Figure 4C).

Finally, arteriolar dilation was assessed during co-incubation with all four chemical interventions. In regards to the overall slopes and the highest ejection current, there was significant decrease in arteriolar reactivity in the WKY-Sham and WKY$\mathrm{CeO}_{2} \mathrm{NP} 53.92 \pm 4.22 \%$, and $56 \pm 6.13 \%$, respectively vs. $7.08 \pm$ $11.26 \%$, and $15.82 \pm 1.50 \%$ during incubation) (Figures 3D, 4D). In the SH groups, there was no significant changes in arteriolar vasodilation in the $\mathrm{SH}$-Sham group, but there was a significant increase in dilation in the $\mathrm{SH}-\mathrm{CeO}_{2} \mathrm{NP}$ group $(43.76 \pm 4.33 \%$ vs. $72.33 \pm 6.26 \%$ during incubation) (Figure 4D). Overall, 

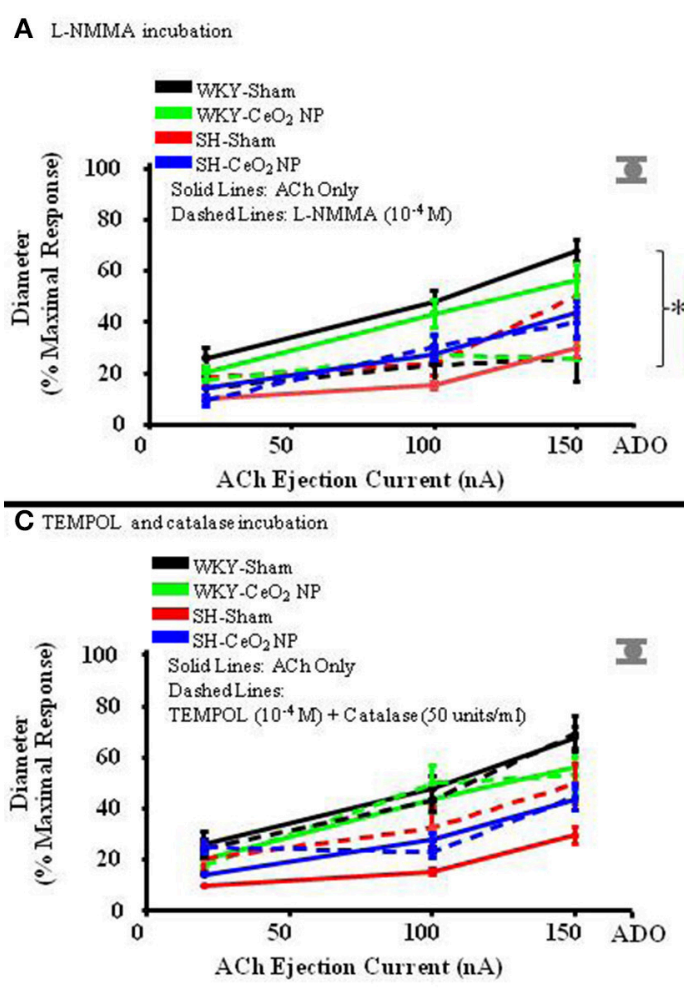

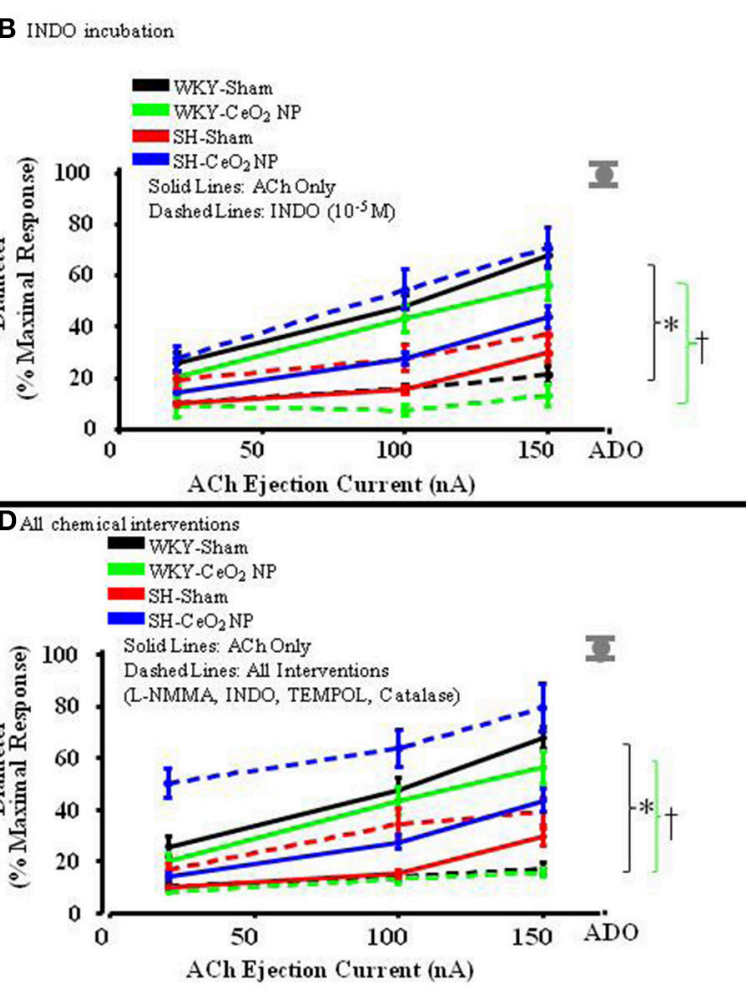

FIGURE 3 | The line graphs are the arterioles overall response to the various chemical interventions. (A) The role of NO was assessed during incubation with L-NMMA ( $n=14-18)$. This incubation resulted in a significant difference in the overall slopes of the dose-response determination within the WKY groups only. (B) The role of COX products was assessed during incubation with INDO ( $n=9-14)$. This incubation resulted in a significant difference in the overall slopes of the dose-response determination within the WKY groups only. (C) Local ROS was scavenged during incubation with TEMPOL and catalase $(n=6-18)$. This incubation resulted in no changes in the overall slopes of the dose-response determination in any of the four treatment groups. (D) ACh-induced vasodilation was assessed during co-incubation with the four chemical interventions $(n=10-15)$. This incubation resulted in a significant difference in the overall slopes of the dose-response determination within the WKY groups only. The gray mark represents the maximal dilation observed during incubation with ADO at the end of the experiment. The brackets indicated significant differences in the overall slopes of the dose-determination. ${ }^{*} p \leq 0.05$ vs. WKY-Sham, ${ }^{\dagger} p \leq 0.05$ vs. WKY-CeO 2 NP.

these data provide initial evidence that there are differential contributions of NO, COX products, and ROS to the observed vasodilation after $\mathrm{CeO}_{2} \mathrm{NP}$ injection exposure in the $\mathrm{SH}$ rats. The increase in microvascular reactivity during TEMPOL and catalase incubation in the SH-Sham group (which was similar to the $\mathrm{SH}-\mathrm{CeO}_{2} \mathrm{NP}$ group), provides evidence that $\mathrm{CeO}_{2} \mathrm{NP}$ may act as an anti-oxidant in vivo.

\section{Microvascular Oxidative Stress}

There was a significant increase in microvascular oxidative stress in the SH-Sham group compared to the WKY groups (Figures 5A,B). The level of oxidative stress in the $\mathrm{SH}$ rats was significantly decreased following $\mathrm{CeO}_{2} \mathrm{NP}$ exposure and the level of oxidative stress in the $\mathrm{SH}-\mathrm{CeO}_{2} \mathrm{NP}$ group was similar to the WKY-Sham group (Figures 5A,B). There were also no significant differences between the WKY-Sham and WKY-CeO 2 NP groups (Figures 5A,B). Taken together, these results provide evidence that $\mathrm{CeO}_{2} \mathrm{NP}$ have anti-oxidant activity in vivo.

\section{Systemic Inflammation and Biomarkers}

Venular leukocyte flux was assessed in all four groups. There was a significant increase in leukocyte flux in the SH-Sham group compared to the WKY-Sham (34 \pm 4 vs. $17 \pm 3$ cells/min), and WKY-CeO 2 NP ( $34 \pm 4$ vs. $21 \pm 2$ cells/min) groups (Figure 6A). This flux was significantly decreased in the $\mathrm{SH}$ animals following exposure to $\mathrm{CeO}_{2} \mathrm{NP}(15 \pm 2$ vs. $34 \pm 4$ cells $/ \mathrm{min}$ ) (Figure 6A). There was also no change in leukocyte flux between the WKY-Sham and $\mathrm{WKY}^{-\mathrm{CeO}_{2} \mathrm{NP}}$ groups (Figure 6A). Pro-inflammatory cytokines were analyzed in harvested plasma. There were no significant differences in IFN- $\gamma$, IL-4, IL-5, IL-6, IL-13, and KC/GRO between the groups (data not shown). There was a significant increase in IL-10 and TNF- $\alpha$ in the WKY-CeO 2 NP group compared to the other three groups (IL-10: $20.60 \pm 4.92 \mathrm{pg} / \mathrm{ml}$ vs. $10.24 \pm 1.09 \mathrm{pg} / \mathrm{ml}$, average of WKY-Sham, SH-Sham, and $\mathrm{SH}-\mathrm{CeO}_{2}$ NP groups; TNF- $\alpha$ : $12.12 \pm 1.38 \mathrm{pg} / \mathrm{ml}$ vs. $6.9 \pm 0.45 \mathrm{pg} / \mathrm{ml}$, average of WKY-Sham, $\mathrm{SH}-\mathrm{Sham}$, and $\mathrm{SH}-\mathrm{CeO}_{2} \mathrm{NP}$ groups) (Figures 6B,C). Finally, there was a decrease in IL- $1 \beta$ in the SH-Sham and $\mathrm{SH}-\mathrm{CeO}_{2}$ $\mathrm{NP}$ groups compared to both WKY groups $(1.58 \pm 1.03 \mathrm{pg} / \mathrm{ml}$ vs. $39.64 \pm 11.37 \mathrm{pg} / \mathrm{ml}$, average of WKY-Sham and WKY$\mathrm{CeO}_{2} \mathrm{NP}$ groups) (Figure 6D). Taken together these results provide evidence that injected $\mathrm{CeO}_{2} \mathrm{NP}$ may alter inflammatory signaling pathways in both normotensive and hypertensive animals. 


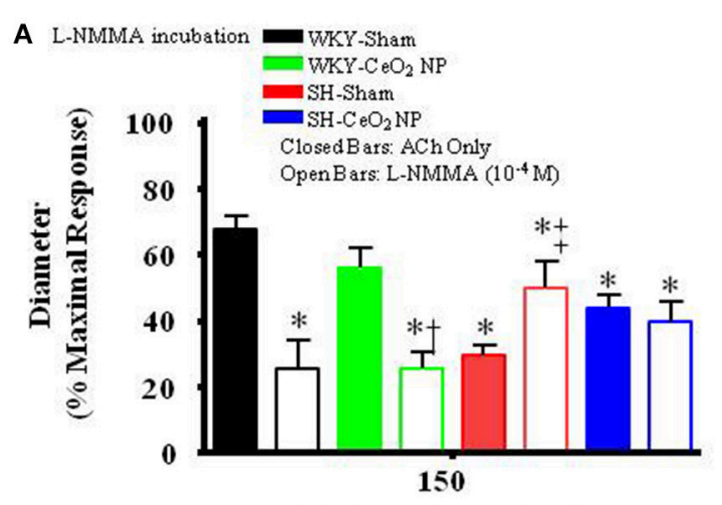

ACh Ejection Current (nA)
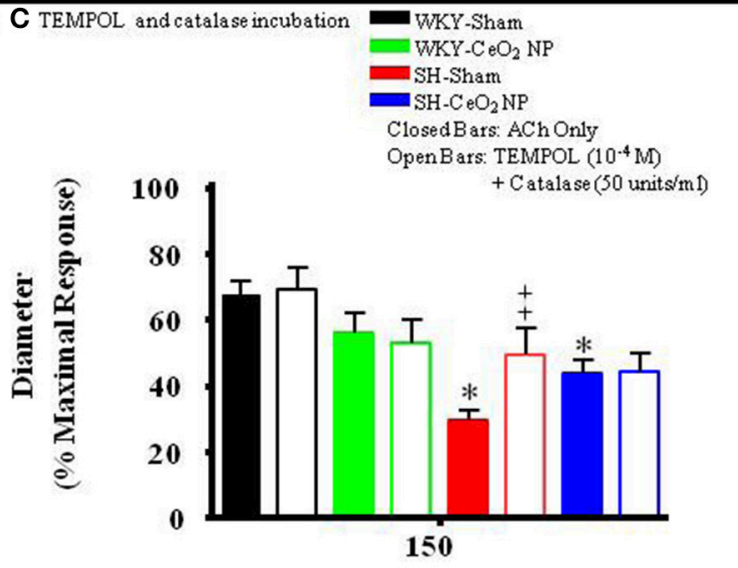

ACh Ejection Current (nA)

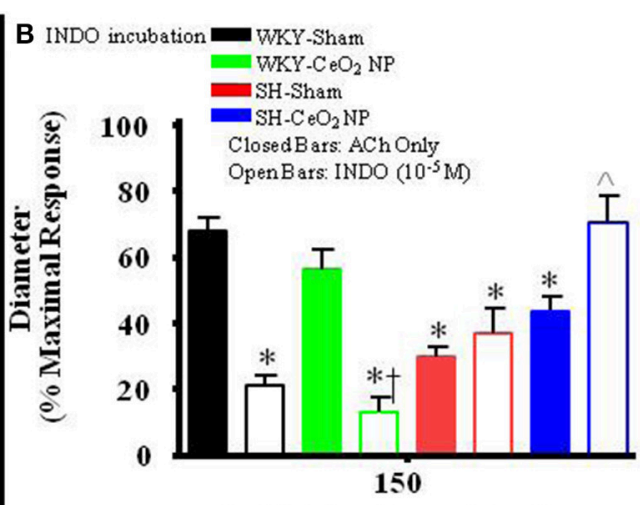

ACh Ejection Current (nA)

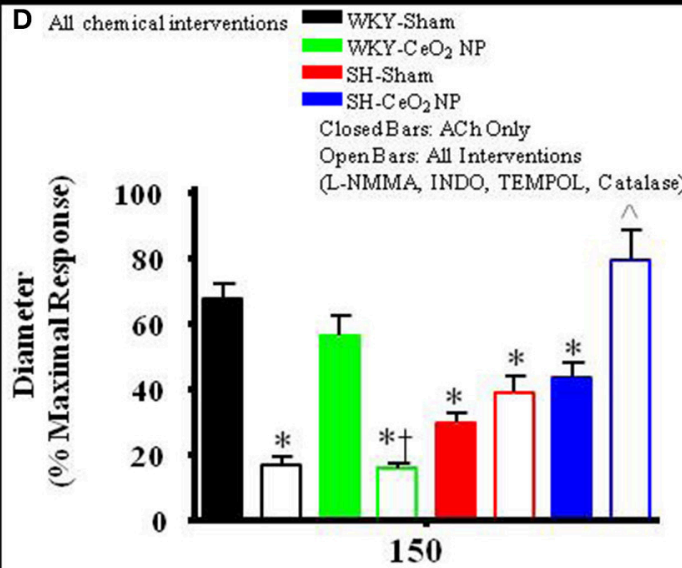

ACh Ejection Current (nA)

FIGURE 4 | The bar graph is the dilation that was observed at $150 \mathrm{nA}$ for each animal group in the presence of the selected chemical intervention. (A) The role of NO was assessed during incubation with L-NMMA ( $n=14-18)$. This incubation resulted in a significant decrease in arteriolar vasodilation in the WKY groups. There was a significant increase in vasodilation during incubation in the $\mathrm{SH}$-Sham group but there was no change in $\mathrm{ACh}$-induced dilation in the $\mathrm{SH}-\mathrm{CeO} \mathrm{NP}_{2}$ group. (B) The role of COX products was assessed during incubation with INDO $(n=9-14)$. This incubation resulted in a significant decrease in arteriolar vasodilation in the WKY groups. There was no change in vasodilation in the $\mathrm{SH}-\mathrm{Sham}$ group, but there was a significant increase in vasodilation following $\mathrm{CeO} 2 \mathrm{NP}\left(\mathrm{SH}_{-} \mathrm{CeO}_{2}\right.$ NP). (C) Local ROS was scavenged during incubation with TEMPOL and catalase $(n=6-18)$. This incubation resulted in no change in arteriolar vasodilation in the WKY groups and the $\mathrm{SH}-\mathrm{CeO}_{2} \mathrm{NP}$ group. There was increase in vasodilation in the $\mathrm{SH}$-Sham group during incubation. (D) ACh-induced vasodilation was assessed during co-incubation with the four chemical interventions $(n=10-15)$. This incubation resulted in a significant decrease in arteriolar vasodilation in the WKY groups. There was no change in vasodilation in the $\mathrm{SH}$-Sham group but there was a significant increase in vasodilation following $\mathrm{CeO} \mathrm{NP}_{2}\left(\mathrm{SH}-\mathrm{CeO} \mathrm{NP}_{2}\right.$. The open bars represent responses to ACh in the presence of a chemical mediator. ${ }^{*} p \leq 0.05$ vs. WKY-Sham, ${ }^{\dagger} p \leq 0.05$ vs. WKY-CeO 2 NP, ${ }^{\ddagger} p \leq 0.05$ vs. SH-Sham, ${ }^{\wedge} p \leq 0.05$ vs. $\mathrm{SH}-\mathrm{CeO}_{2} \mathrm{NP}$.

\section{DISCUSSION}

To our knowledge, this is the first study to investigate the in vivo anti-oxidant potential of $\mathrm{CeO}_{2} \mathrm{NP}$ in a hypertensive animal model. The first major finding of this study is that $\mathrm{CeO}_{2}$ $\mathrm{NP}$ have anti-oxidant potential in vivo resulting in decreased microvascular dysfunction and oxidative stress that is associated with hypertension. The second finding of this study is that there were changes in leukocyte adhesion/rolling and cytokine expression, which indicated that $\mathrm{CeO}_{2} \mathrm{NP}$ might influence thrombosis risk and inflammation.

Intravenously injected $\mathrm{CeO}_{2} \mathrm{NP}$ significantly reduced the level of oxidative stress in the $\mathrm{SH}$ rats, which contributed to decreased microvascular dysfunction. This finding supports the notion that
$\mathrm{CeO}_{2} \mathrm{NP}$ act as an anti-oxidant, and this finding is corroborated by numerous studies (Colon et al., 2010; Estevez et al., 2011; Kim et al., 2012). Despite this positive result, previous studies have shown a decrease in vascular function following $\mathrm{CeO}_{2} \mathrm{NP}$ exposure (Wingard et al., 2011; Minarchick et al., 2015). These disparate effects may be due to changes in the basal level of ROS and the animal model.

$\mathrm{SH}$ rats have an increased basal level of ROS, that was not present in the Sprague-Dawley rats that were used in previous studies (LeBlanc et al., 2010). An increase in ROS generation is also observed during radiation treatments and stroke, where these ENM were shown to be beneficial in a therapeutic capacity. This conceptual need for an increased basal level of ROS is also supported in vitro. Cardiac progenitor cells and cardiomyocytes 

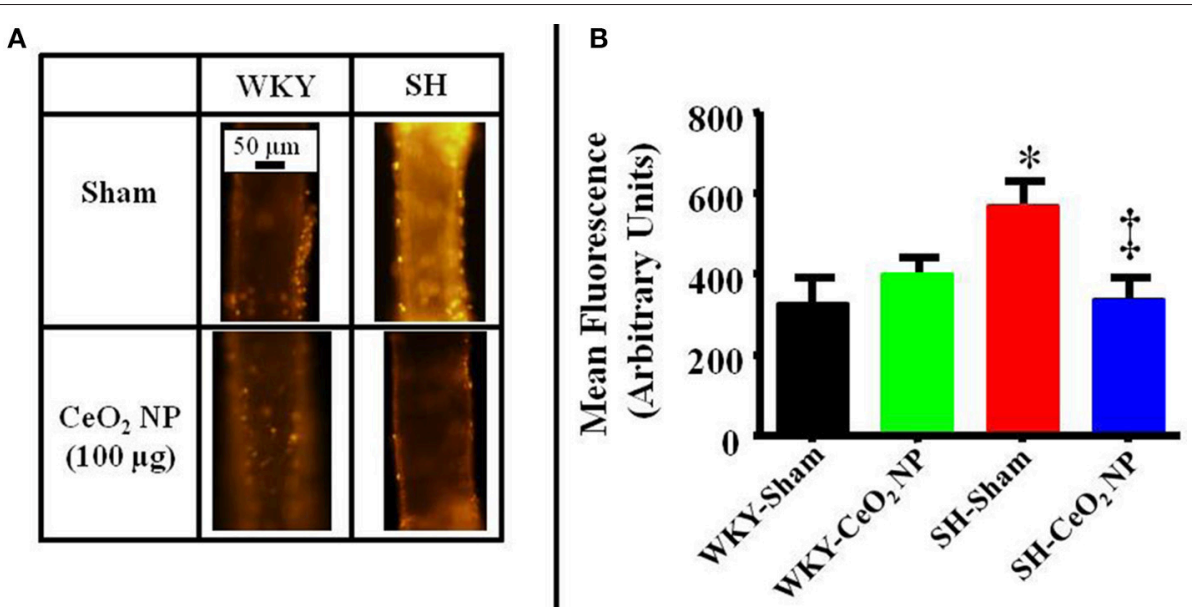

FIGURE 5 | (A) Representative ethidium bromide images indicating an increase in oxidative stress in the SH-Sham group. (B) Quantitative analysis of the ethidium bromide images revealed a significant increase in vascular oxidative stress in the $\mathrm{SH}$-Sham group that was reduced in the $\mathrm{SH}-\mathrm{CeO} 2$ group $(n=5-7)$. These levels were similar to the WKY-Sham and WKY-CeO 2 NP groups. ${ }^{*} p \leq 0.05$ vs. WKY-Sham, ${ }^{\ddagger} p \leq 0.05$ vs. SH-Sham.

were protected from high ROS levels when $\mathrm{CeO}_{2} \mathrm{NP}$ were present (Niu et al., 2011; Pagliari et al., 2012). Furthermore, there were not high initial levels of ROS production in studies that reported an increase in ROS following $\mathrm{CeO}_{2}$ NP exposure (Park et al., 2008; Horie et al., 2011). When taken together these studies support the hypothesis that $\mathrm{CeO}_{2} \mathrm{NP}$ work optimally as an antioxidant when there are elevated levels of ROS prior to or in conjunction with exposure.

In addition to the potential changes in ROS, the selected animal model may also affect the lack of microvascular influences following $\mathrm{CeO}_{2} \mathrm{NP}$ in the WKY rats. Exposures to ENM and particulate matter have yielded different results in various strains of animals, which indicated that genetic background may play a vital role in determining the in vivo effects of nanomaterials (Gottipolu et al., 2009; Wingard et al., 2011). Both the WKY and $\mathrm{SH}$ animals are inbred strains compared to the outbred Sprague-Dawley rat used in other studies with $\mathrm{CeO}_{2}$ NP. Genetic modifications have been shown to alter the effects of ENM exposure (Wingard et al., 2011). $\mathrm{CeO}_{2} \mathrm{NP}$ exposed mice have an increase in pulmonary inflammation and vascular dysfunction; however, when these mice were genetically modified to knockout mast cell production the inflammatory and vascular effects were absent (Wingard et al., 2011). Therefore, it is reasonable to speculate that genetic differences between the WKY, SH, and Sprague-Dawley rat lineages may contribute to the differences in the observed microvascular reactivity. Further studies are required to investigate potential genetic differences and their influence on the cardiovascular outcomes following ENM exposure.

Finally, the experimental techniques utilized in various vascular function assessments may also have contributed to the differential microvascular effects observed in this and other studies (Wingard et al., 2011; Minarchick et al., 2015). Previous microvascular assessments were completed using pressure or wire myography. These techniques allowed for the determination of specific influences of certain agonists without the confounding influences of blood flow and autonomic innervation (Minarchick et al., 2015). However, the vascular assessments in this manuscript were conducted using intravital microscopy to determine if the observations from previous experiments persisted in the whole animal. Therefore, the lack of overt endothelium-dependent and -independent microvascular dysfunction in the WKY rats could be due in part to the activation of compensatory mechanisms, sympathetic stimulation, and/or blood flow, which may hide underlying microvascular dysfunction.

Despite the partial improvement in microvascular dysfunction after exposure, $\mathrm{CeO}_{2} \mathrm{NP}$ could not completely restore normal microvascular function in the $\mathrm{SH}$ animal model (Figure 1). This lack of an overall improvement could be due to arachidonic acid (AA) metabolism via COX. This study provides evidence that $\mathrm{CeO}_{2} \mathrm{NP}$ exposure results in an apparent shift between NOS and COX activity, resulting potentially in increased prostaglandin production. Furthermore, the changes in AA signaling appear to be unique to the $\mathrm{CeO}_{2} \mathrm{NP}$ exposure in the $\mathrm{SH}$ animal model. An increase in prostaglandin production can affect microvascular reactivity by influencing both vasodilation and vasoconstriction. Based on improved vasodilation during INDO incubation in the $\mathrm{SH}-\mathrm{CeO}_{2} \mathrm{NP}$ animals, it can be speculated that $\mathrm{CeO}_{2} \mathrm{NP}$ exposure increases thromboxane $\mathrm{A}_{2}$ activity, which would result in vasoconstriction (Figures 3, 4). This increased influence on vasoconstriction could prevent the arterioles from fully dilating in response to $\mathrm{ACh}$. In addition to potential thromboxane $\mathrm{A}_{2}$ alterations, a potential increase in arteriolar vasoconstriction could be due to changes in autonomic regulation, which maybe from changes in sympathetic stimulation. It should also be noted there was an increase in dilation during incubation with L-NMMA in the SH-Sham animals. The source of this improved dilation is unknown, but may be linked to change in signaling in the hypertensive model, including NOS uncoupling, 


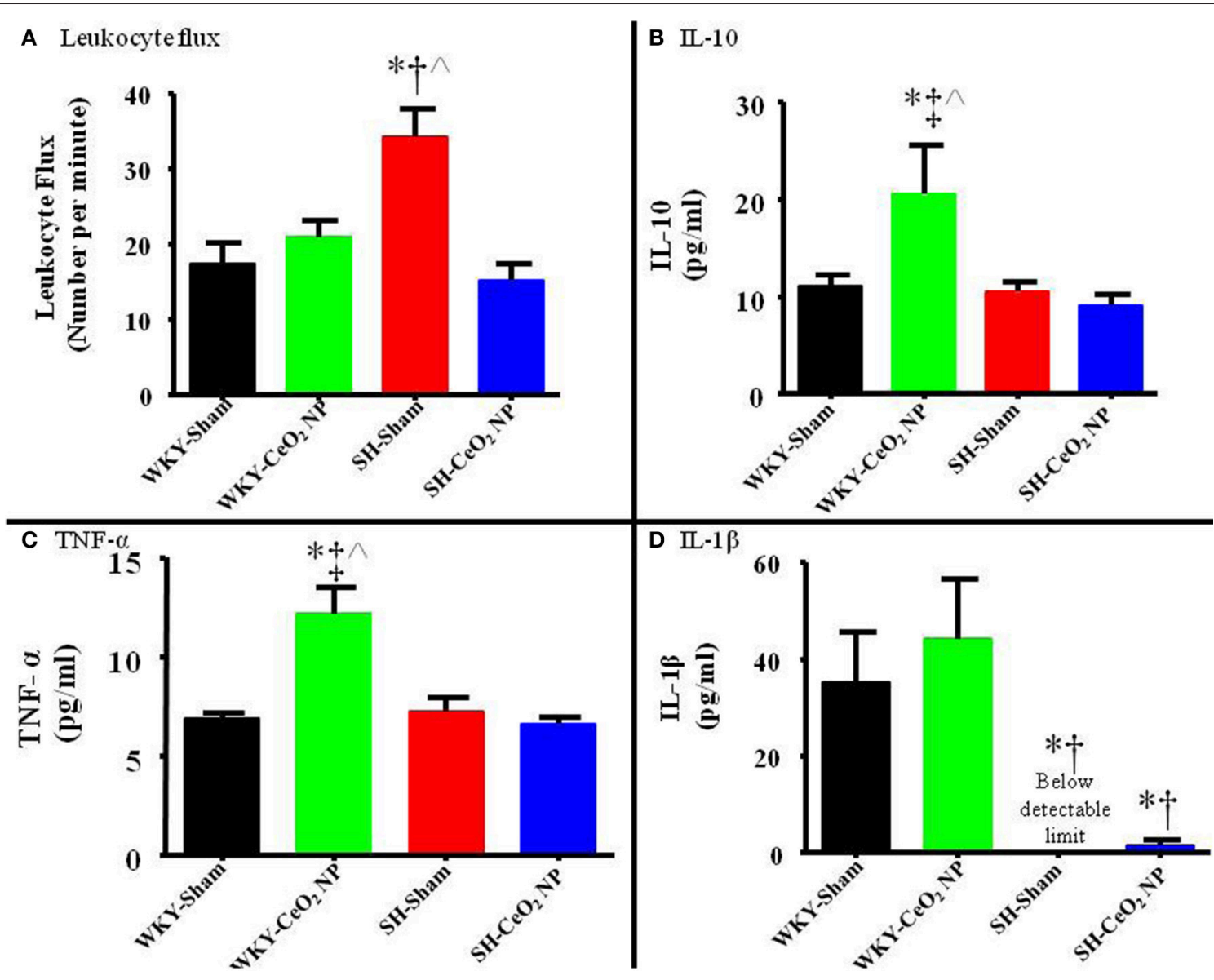

FIGURE 6 | (A) Leukocyte flux was assessed in venules during intravital microscopy. There was a significant increase in leukocyte flux in the SH-Sham group, which was decreased following $\mathrm{CeO}_{2} \mathrm{NP}$ exposure $(n=12-15)$. (B) Plasma IL-10 levels were significantly increased in the WKY-CeO 2 NP, but not in the other three groups $(N=7)$. (C) Plasma TNF- $\alpha$ levels were significantly increased in the $W K Y-C_{2} O_{2} N P$, but not in the other three groups $(N=6-7)$. (D) Plasma IL-1 $\beta$ levels were significantly decreased in the $\mathrm{SH}-\mathrm{Sham}$ and $\mathrm{SH}-\mathrm{CeO}_{2} \mathrm{NP}$ groups, but were unaltered in the WKY-CeO 2 NP group $(\mathrm{N}=6-7)$. ${ }^{*} p \leq 0.05$ vs. WKY-Sham, ${ }^{\dagger} p \leq 0.05$ vs. WKY-CeO 2 NP, ${ }^{\ddagger} p \leq 0.05$ vs. SH-Sham, ${ }^{\wedge} p \leq 0.05$ vs. $\mathrm{SH}-\mathrm{CeO}_{2} \mathrm{NP}$.

increased prostacyclin production and improved endotheliumderived hyperpolarizing factor signaling (Nishikawa et al., 2000; Parkington et al., 2008). Additional studies will be needed to determine the influence of $\mathrm{CeO}_{2} \mathrm{NP}$ on AA signaling, COX activation, and autonomic regulation.

This study provides promising evidence of the in vivo antioxidant potential of $\mathrm{CeO}_{2} \mathrm{NP}$; however, it is currently unclear if $\mathrm{CeO}_{2} \mathrm{NP}$ are operating at their maximal efficiency in vivo. One of the primary factors that could affect the cardiovascular outcomes of $\mathrm{CeO}_{2} \mathrm{NP}$ (and ENM in general) is the dose. The dose used in this study was $\sim 0.42 \mathrm{mg} / \mathrm{kg}$ based on an average animal weight of $240 \mathrm{~g}$. This dose was on the lower end of the published effective doses $(0.4-0.7 \mathrm{mg} / \mathrm{kg})$ used to protect mice from stroke damage (Kim et al., 2012). Therefore, it is reasonable to speculate that increasing the dose may improve $\mathrm{CeO}_{2} \mathrm{NP}$ anti-oxidant effectiveness in hypertensive animals. Dose refinement could potentially result in a further improvement in microvascular function and decreased oxidative stress. This need for further dose refinement also highlights a limitation of this study. It was not possible to determine the amount of $\mathrm{CeO}_{2} \mathrm{NP}$ that accumulated within the vascular wall; therefore, it is unclear at this time if the observed results are due to direct or indirect interactions with $\mathrm{CeO}_{2} \mathrm{NP}$. Independent of direct or indirect effects, understanding the cardiovascular influences, particularly in regards to the effective dose, is vital if $\mathrm{CeO}_{2} \mathrm{NP}$ are to be developed as a pharmaceutical agent. Additionally, the effective dose needs to be better understood because research has shown that higher concentrations of $\mathrm{CeO}_{2} \mathrm{NP}$ may result in decreased anti-oxidant activity and an increase in pro-oxidant activity (Horie et al., 2011). This shift in activity highlights the need to investigate various doses within a model, and additional dosing paradigms will need to be tested to explore the full potential of $\mathrm{CeO}_{2} \mathrm{NP}$ to improve the microvascular dysfunction associated with hypertension.

Another factor that may influence the efficiency of $\mathrm{CeO}_{2} \mathrm{NP}$ anti-oxidant activity is the primary size of the nanoparticles. The ENM used in this study and in another stroke study had a primary size of $2-4 \mathrm{~nm}$; however, studies that used larger 
ENM (>20 nm) have been associated with an increase in ROS generation as opposed to a decrease (Park et al., 2008; Kim et al., 2012). This difference in the cellular effects has also been observed with other ENM. Silver nanoparticles with a diameter $<40 \mathrm{~nm}$ had increased cell permeability and toxicity vs. their larger counterparts (>40 nm) (Sheikpranbabu et al., 2010; Trickler et al., 2010). This not only illustrates the importance of characterizing the size of the ENM used, but also how a small change in ENM size can alter both their physiochemical characteristics and their cellular and cardiovascular effects.

The proposed anti-oxidant activity is most likely connected to the valence states $\left(\mathrm{Ce}^{3+}\right.$ and $\left.\mathrm{Ce}^{4+}\right)$ that are present in $\mathrm{CeO}_{2}$ NP. Both valence states may react with any free radical, but research has shown that depending on the valence state this ENM will preferentially react with various free radicals. Under in vitro conditions, $\mathrm{Ce}^{3+}$ preferentially reacts with the superoxide and $\mathrm{Ce}^{4+}$ reacts with $\mathrm{NO}(\mathrm{Xu}$ and $\mathrm{Qu}, 2014)$. The $\mathrm{CeO}_{2} \mathrm{NP}$ used in this study were $\sim 19 \% \mathrm{Ce}^{3+}$ and $81 \% \mathrm{Ce}^{4+}$ indicating they may react more readily with $\mathrm{NO}$; however in this study $\mathrm{CeO}_{2} \mathrm{NP}$ exposure did not appear to impair NO bioavailability. This apparent lack of NO scavenging may be due to changes in the valence state of $\mathrm{CeO}_{2} \mathrm{NP}$ following exposure; however, it is currently unknown to what extent the valence state of $\mathrm{CeO}_{2} \mathrm{NP}$ is modified following in vivo exposure (Hayes et al., 2002).

$\mathrm{CeO}_{2} \mathrm{NP}$ exposure has also been associated with changes in inflammation. Similar to this study, others have shown an increase in pro-inflammatory cytokines, changes in the leukocyte flux, and inflammatory NOS expression following in vivo $\mathrm{CeO}_{2}$ NP exposure, but these results are often inconsistent (Hirst et al., 2009; Cho et al., 2010; Hussain et al., 2012). In this study, an increase in cytokine expression (e.g., TNF- $\alpha$ and IL10) was present in the normotensive $\mathrm{CeO}_{2} \mathrm{NP}$ exposed animals and it has been well established that inflammation is associated with microvascular dysfunction (Nurkiewicz et al., 2006; LeBlanc et al., 2009). Furthermore, an increase in TNF- $\alpha$ and IL-10 is associated with the activation of macrophages via toll-like receptors, which further supports $\mathrm{CeO}_{2} \mathrm{NP}$ potential to modify inflammation (Mosser, 2003). Finally, it should be noted that it is unclear if $\mathrm{CeO}_{2} \mathrm{NP}$ preferentially effect ROS or inflammation and further studies are needed to address this issue.

Additionally, these changes in inflammatory cytokines and leukocyte flux could indicate that $\mathrm{CeO}_{2} \mathrm{NP}$ modify thrombosis development. The increase in leukocyte flux in the $\mathrm{SH}$ rats provide indirect evidence for endothelial cell activation, which results in the production of various adhesion proteins and factors essential for fibrinolysis (e.g., plasminogen activator inhibitor-1). Plasminogen activator inhibitor-1 (PAI-1) is secreted by macrophages, endothelial cells and vascular smooth muscle cells. Furthermore, this factor is controlled by oxidative stress. Studies with nano-copper oxide have shown an increase in PAI1 secretion following exposure and it is possible that this factor is also elevated in the $\mathrm{SH}$-Sham rats, thus increasing the risk of thrombosis ( $\mathrm{Yu}$ et al., 2010b). However, following $\mathrm{CeO}_{2} \mathrm{NP}$ exposure there is a decrease in leukocyte flux and oxidative stress in the $\mathrm{SH}$ rats, which could indicate a decreased thrombosis risk. However, the potential increased thromboxane $\mathrm{A}_{2}$ activity (in the $\mathrm{CeO}_{2} \mathrm{NP}$ exposed $\mathrm{SH}$ rats) may be linked to the activation of platelets, which would increase the risk of thrombosis in these animals. Overall, it appears that $\mathrm{CeO}_{2} \mathrm{NP}$ influences the thrombotic potential in $\mathrm{SH}$ rats, but at this time, it is unclear if they increase or decrease this risk and further studies are needed to understand these influences.

It should also be noted that there was no microvascular impairment in the normotensive rats after exposure despite an increase in pro-inflammatory cytokines. This lack of impairment maybe due to the time post-exposure $(24 \mathrm{~h})$ when reactivity was assessed and the lack of increased leukocyte adhesion and rolling in the WKY group further supports this notion. If the animals were exposed for a longer period of time (over $24 \mathrm{~h}$ ), an increase in the activation of adhesion molecules and, ultimately, leukocyte extravasation may lead to an increase in microvascular dysfunction and thrombosis development.

Finally, the time of inflammatory assessments may also contribute to the observed changes in circulating cytokines. TNF$\alpha$ is classically considered a pro-inflammatory cytokine that is involved in macrophage activation, whereas IL-10 is often considered an anti-inflammatory cytokine because is it capable of inhibiting TNF- $\alpha$ and IFN- $\gamma$ (Feghali and Wright, 1997). In this study, it is possible that at $24 \mathrm{~h} \mathrm{IL-10}$ is beginning to increase, whereas TNF- $\alpha$ may be beginning to decrease, and this change in expression could result in the brief elevation of both cytokines. Additionally, based on these results, it is reasonable to speculate that $\mathrm{CeO}_{2} \mathrm{NP}$ may have anti-inflammatory potential due to the increase in IL-10. Furthermore, SH rats typically have chronic inflammation, which contributes to their microvascular dysfunction (Sanz-Rosa et al., 2005). This study showed limited changes in the expression of pro-inflammatory cytokines in the $\mathrm{SH}$ animals and this lack of cytokine production may due to the age of the animals used in this study. Additionally, these limited cytokine and leukocyte results highlight the need for an extensive time course study to fully understand the effects of $\mathrm{CeO}_{2} \mathrm{NP}$ exposure on inflammation and thrombosis development. Further studies will need to investigate the relationship between $\mathrm{CeO}_{2} \mathrm{NP}$, the inflammatory response, and exposure time in normotensive and hypertensive rats.

In conclusion, this study provides evidence that injected $\mathrm{CeO}_{2} \mathrm{NP}$ decreases microvascular oxidative stress in a high ROS environment, which in turn, improves microvascular function. These results further our understanding of $\mathrm{CeO}_{2} \mathrm{NP}$ behavior in vivo and highlight their therapeutic potential as an antioxidant, particularly in pathologies associated with elevated ROS. Furthermore, this study showed changes in the inflammatory profile following $\mathrm{CeO}_{2} \mathrm{NP}$ exposure. Similarly, it is reasonable to speculate that $\mathrm{CeO}_{2} \mathrm{NP}$ used preemptively would oppose the acute escalation of local ROS levels associated with various injuries and treatments. These changes were primarily observed in the WKY group, which highlight the need for further research on this ENM in order to understand fully its influences on systemic inflammation. Fully understanding how $\mathrm{CeO}_{2} \mathrm{NP}$ act in vivo in both low and high ROS environments is critical for the continued and expanded development of this potential therapeutic agent. 


\section{AUTHOR CONTRIBUTIONS}

VM performed the experiments in this manuscript. TN, PS, and VM all contributed to the development and experimental design of the experiments. Finally, ES provided the $\mathrm{CeO}_{2}$ NP and nanoparticle characterization needed for these studies. All authors reviewed and approved this manuscript prior to submission.

\section{FUNDING}

This work was supported by the following sources: National Institutes of Health R01-ES015022 (TN), K99-ES024783 (PS), the National Science Foundation Cooperative Agreement-1003907 (TN), and DGE-1144676 (VM).

\section{REFERENCES}

Bakker, E. N., Groma, G., Spijkers, L. J., de Vos, J., van Weert, A., van Veen, H., et al. (2014). Heterogeneity in arterial remodeling among sublines of spontaneously hypertensive rats. PLoS ONE 9:e107998. doi: 10.1371/journal.pone.01 07998

Benov, L., Sztejnberg, L., and Fridovich, I. (1998). Critical evaluation of the use of hydroethidine as a measure of superoxide anion radical. Free Radic. Biol. Med. 25, 826-831. doi: 10.1016/S0891-5849(98)00163-4

Boegehold, M. A., and Bohlen, H. G. (1988). Arteriolar diameter and tissue oxygen tension during muscle contraction in hypertensive rats. Hypertension 12, 184-191. doi: 10.1161/01.HYP.12.2.184

Bohlen, H. G., Henrich, H., Gore, R. W., and Johnson, P. C. (1978). Intestinal muscle and mucosal blood flow during direct sympathetic stimulation. Am. J. Physiol. 235, H40-H45.

Borm, P. J., Robbins, D., Haubold, S., Kuhlbusch, T., Fissan, H., Donaldson, K., et al. (2006). The potential risks of nanomaterials: a review carried out for ECETOC. Part. Fibre Toxicol. 3:11. doi: 10.1186/1743-8977-3-11

Brito, R., Castillo, G., González, J., Valls, N., and Rodrigo, R. (2015). Oxidative stress in hypertension: mechanisms and therapeutic opportunities. Exp. Clin. Endocrinol. Diabetes 123, 325-335. doi: 10.1055/s-0035-1548765

Celardo, I., Traversa, E., and Ghibelli, L. (2011). Cerium oxide nanoparticles: a promise for applications in therapy. J. Exp. Ther. Oncol. 9, 47-51.

Cho, W. S., Duffin, R., Poland, C. A., Howie, S. E., MacNee, W., Bradley, M., et al. (2010). Metal oxide nanoparticles induce unique inflammatory footprints in the lung: important implications for nanoparticle testing. Environ. Health Perspect. 118, 1699-1706. doi: 10.1289/ehp.1002201

Colon, J., Herrera, L., Smith, J., Patil, S., Komanski, C., Kupelian, P., et al. (2009). Protection from radiation-induced pneumonitis using cerium oxide nanoparticles. Nanomedicine 5, 225-231. doi: 10.1016/j.nano.2008. 10.003

Colon, J., Hsieh, N., Ferguson, A., Kupelian, P., Seal, S., Jenkins, D. W., et al. (2010). Cerium oxide nanoparticles protect gastrointestinal epithelium from radiation-induced damage by reduction of reactive oxygen species and upregulation of superoxide dismutase 2. Nanomedicine 6, 698-705. doi: 10.1016/j.nano.2010.01.010

Dunnick, K. M., Pillai, R., Pisane, K. L., Stefaniak, A. B., Sabolsky, E. M., and Leonard, S. S. (2015). The effect of cerium oxide nanoparticle valence state on reactive oxygen species and toxicity. Biol. Trace Elem. Res. 166, 96-107. doi: 10.1007/s12011-015-0297-4

Estevez, A. Y., Pritchard, S., Harper, K., Aston, J. W., Lynch, A., Lucky, J. J., et al. (2011). Neuroprotective mechanisms of cerium oxide nanoparticles in a mouse hippocampal brain slice model of ischemia. Free Radic. Biol. Med. 51, 1155-1163. doi: 10.1016/j.freeradbiomed.2011.06.006

Feghali, C. A., and Wright, T. M. (1997). Cytokines in acute and chronic inflammation. Front. Biosci. 2, d12-d26.

\section{ACKNOWLEDGMENTS}

The authors would like to thank Carroll McBride for his expert technical assistance in this study and Alaeddin Abukabda for his critical analysis of this manuscript. The authors would also like to thank the members of Dr. Edward Sabolsky's laboratory and Katarzyna Sabolsky for manufacturing and characterizing the $\mathrm{CeO}_{2} \mathrm{NP}$ used in this study. Finally, the authors thank Dr. Kathleen Brundage for her technical assistance and the use of the West Virginia University (WVU) Flow Cytometry Core Facility for the analysis of the pro-inflammatory cytokine analysis. The WVU Flow Cytometry Core Facility is supported by the following grants: MBRCC CoBRE grant: GM103488/RR032138, ARIA S10 grant: RR020866, Fortess S10 grant: OD016165, and WV InBRE grant: GM103434.

Félétou, M., and Vanhoutte, P. M. (2006). Endothelial dysfunction: a multifaceted disorder (The Wiggers Award Lecture). Am. J. Physiol. Heart Circ. Physiol. 291, H985-H1002. doi: 10.1152/ajpheart.00292.2006

Gojova, A., Lee, J. T., Jung, H. S., Guo, B., Barakat, A. I., and Kennedy, I. M. (2009). Effect of cerium oxide nanoparticles on inflammation in vascular endothelial cells. Inhal. Toxicol. 21(Suppl. 1), 123-130. doi: 10.1080/08958370902942582

Gottipolu, R. R., Wallenborn, J. G., Karoly, E. D., Schladweiler, M. C., Ledbetter, A. D., Krantz, T., et al. (2009). One-month diesel exhaust inhalation produces hypertensive gene expression pattern in healthy rats. Environ. Health Perspect. 117, 38-46. doi: 10.1289/ehp.11647

Hayes, S. A., Yu, P., OKeefe, T. J., OKeefe, M. J., and Stoffer, J. O. (2002). The phase stability of cerium species in aqueous systems I. E-pH diagram for the Ce-HClO4-H2O system. J. Electrochem. Soc. 149, C623-C630. doi: $10.1149 / 1.1516775$

Heckert, E. G., Karakoti, A. S., Seal, S., and Self, W. T. (2008). The role of cerium redox state in the SOD mimetic activity of nanoceria. Biomaterials 29, 2705-2709. doi: 10.1016/j.biomaterials.2008.03.014

Hirst, S. M., Karakoti, A. S., Tyler, R. D., Sriranganathan, N., Seal, S., and Reilly, C. M. (2009). Anti-inflammatory properties of cerium oxide nanoparticles. Small 5, 2848-2856. doi: 10.1002/smll.200901048

Horie, M., Nishio, K., Kato, H., Fujita, K., Endoh, S., Nakamura, A., et al. (2011). Cellular responses induced by cerium oxide nanoparticles: induction of intracellular calcium level and oxidative stress on culture cells. J. Biochem. 150, 461-471. doi: 10.1093/jb/mvr081

Hussain, S., Al-Nsour, F., Rice, A. B., Marshburn, J., Ji, Z., Zink, J. I., et al. (2012). Cerium dioxide nanoparticles do not modulate the lipopolysaccharide-induced inflammatory response in human monocytes. Int. J. Nanomed. 7, 1387-1397. doi: $10.2147 /$ IJN.S29429

Kelkar, S. S., and Reineke, T. M. (2011). Theranostics: combining imaging and therapy. Bioconjug. Chem. 22, 1879-1903. doi: 10.1021/bc200151q

Kim, C. K., Kim, T., Choi, I. Y., Soh, M., Kim, D., Kim, Y. J., et al. (2012). Ceria nanoparticles that can protect against ischemic stroke. Angew. Chem. Int. Ed Engl. 51, 11039-11043. doi: 10.1002/anie.201203780

LeBlanc, A. J., Cumpston, J. L., Chen, B. T., Frazer, D., Castranova, V., and Nurkiewicz, T. R. (2009). Nanoparticle inhalation impairs endotheliumdependent vasodilation in subepicardial arterioles. J. Toxicol. Environ. Health A. 72, 1576-1584. doi: 10.1080/15287390903232467

LeBlanc, A. J., Moseley, A. M., Chen, B. T., Frazer, D., Castranova, V., and Nurkiewicz, T. R. (2010). Nanoparticle inhalation impairs coronary microvascular reactivity via a local reactive oxygen species-dependent mechanism. Cardiovasc. Toxicol. 10, 27-36. doi: 10.1007/s12012-009-9060-4

Madero-Visbal, R. A., Alvarado, B. E., Colon, J. F., Baker, C. H., Wason, M. S., Isley, B., et al. (2012). Harnessing nanoparticles to improve toxicity after head and neck radiation. Nanomedicine 8, 1223-1231. doi: 10.1016/j.nano.2011.12.011

Minarchick, V. C., Stapleton, P. A., Fix, N. R., Leonard, S. S., Sabolsky, E. M., and Nurkiewicz, T. R. (2015). Intravenous and gastric cerium dioxide nanoparticle 
exposure disrupts microvascular smooth muscle signaling. Toxicol. Sci. 144, 77-89. doi: 10.1093/toxsci/kfu256

Minarchick, V. C., Stapleton, P. A., Porter, D. W., Wolfarth, M. G., Çiftyürek, E., Barger, M., et al. (2013). Pulmonary cerium dioxide nanoparticle exposure differentially impairs coronary and mesenteric arteriolar reactivity. Cardiovasc. Toxicol. 13, 323-337. doi: 10.1007/s12012-013-9213-3

Morgan, A. R., Evans, D. H., Lee, J. S., and Pulleyblank, D. E. (1979). Review: ethidium fluorescence assay. Part II. enzymatic studies and DNA-protein interactions. Nucleic Acids Res. 7, 571-594. doi: 10.1093/nar/7.3.571

Mosser, D. M. (2003). The many faces of macrophage activation. J. Leukoc. Biol. 73, 209-212. doi: 10.1189/jlb.0602325

Nishikawa, Y., Stepp, D. W., and Chilian, W. M. (2000). Nitric oxide exerts feedback inhibition on EDHF-induced coronary arteriolar dilation in vivo. Am. J. Physiol. Heart Circ. Physiol. 279, H459-H465.

Niu, J., Wang, K., and Kolattukudy, P. E. (2011). Cerium oxide nanoparticles inhibit oxidative stress and nuclear factor-kappaB activation in $\mathrm{H} 9 \mathrm{c} 2$ cardiomyocytes exposed to cigarette smoke extract. J. Pharmacol. Exp. Ther. 338, 53-61. doi: 10.1124/jpet.111.179978

Nurkiewicz, T. R., Porter, D. W., Barger, M., Castranova, V., and Boegehold, M. A. (2004). Particulate matter exposure impairs systemic microvascular endothelium-dependent dilation. Environ. Health Perspect. 112, 1299-1306. doi: 10.1289/ehp.7001

Nurkiewicz, T. R., Porter, D. W., Barger, M., Millecchia, L., Rao, K. M., Marvar, P. J., et al. (2006). Systemic microvascular dysfunction and inflammation after pulmonary particulate matter exposure. Environ. Health Perspect. 114, 412-419. doi: 10.1289/ehp.8413

Nwankwo, T., Yoon, S. S., Burt, V., and Gu, Q. (2013). Hypertension Among Adults in the US: National Health and Nutrition Examination Survey, 20112012. NCHS Data Brief, 133. National Center for Health Statistics, Centers for Disease Control and Prevention, Hyattsville, MD, US Dept of Health and Human Services. Ref Type: Report.

Okamoto, K., Nosaka, S., Yamori, Y., and Matsumoto, M. (1967). Participation of neural factor in the pathogenesis of hypertension in the spontaneously hypertensive rat. Jpn. Heart J. 8, 168-180. doi: 10.1536/ihj.8.168

Pagliari, F., Mandoli, C., Forte, G., Magnani, E., Pagliari, S., Nardone, G., et al. (2012). Cerium oxide nanoparticles protect cardiac progenitor cells from oxidative stress. ACS Nano. 6, 3767-3775. doi: 10.1021/nn2048069

Park, E. J., Choi, J., Park, Y. K., and Park, K. (2008). Oxidative stress induced by cerium oxide nanoparticles in cultured BEAS-2B cells. Toxicology 245, 90-100. doi: 10.1016/j.tox.2007.12.022

Parkington, H. C., Tare, M., and Coleman, H. A. (2008). The EDHF story: the plot thickens. Circ. Res. 102, 1148-1150. doi: 10.1161/CIRCRESAHA.108.177279

Roco, M. C., Mirkin, C. A., and Hersam, M. C. (2010). Nanotechnology Research Directions for Societal Needs in 2020. Retrospective and Outlook. 9-30. World Technology Evaluation Center, Inc. Ref Type: Report.

Sanz-Rosa, D., Oubiña, M. P., Cediel, E., de Las Heras, N., Vegazo, O., Jiménez, J., et al. (2005). Effect of AT1 receptor antagonism on vascular and circulating inflammatory mediators in SHR: role of NF-kappaB/IkappaB system. Am. J. Physiol. Heart Circ. Physiol. 288, H111-H115. doi: 10.1152/ajpheart.01061.2003

Sheikpranbabu, S., Kalishwaralal, K., Lee, K. J., Vaidyanathan, R., Eom, S. H., and Gurunathan, S. (2010). The inhibition of advanced glycation end-productsinduced retinal vascular permeability by silver nanoparticles. Biomaterials 31 , 2260-2271. doi: 10.1016/j.biomaterials.2009.11.076

Stapleton, P. A., and Nurkiewicz, T. R. (2014). Vascular distribution of nanomaterials. Wiley Interdiscip. Rev. Nanomed. Nanobiotechnol. 6, 338-348. doi: 10.1002/wnan.1271

Sun, D., Messina, E. J., Kaley, G., and Koller, A. (1992). Characteristics and origin of myogenic response in isolated mesenteric arterioles. Am. J. Physiol. $263(\mathrm{Pt}$ 2), H1486-H1491.

Suzuki, H., Swei, A., Zweifach, B. W., and Schmid-Schonbein, G. W. (1995). In vivo evidence for microvascular oxidative stress in spontaneously hypertensive rats. hydroethidine microfluorography. Hypertension 25, 1083-1089. doi: 10.1161/01.HYP.25.5.1083

Trickler, W. J., Lantz, S. M., Murdock, R. C., Schrand, A. M., Robinson, B. L., Newport, G. D., et al. (2010). Silver nanoparticle induced bloodbrain barrier inflammation and increased permeability in primary rat brain microvessel endothelial cells. Toxicol. Sci. 118, 160-170. doi: 10.1093/toxsci/ kfq244

Wingard, C. J., Walters, D. M., Cathey, B. L., Hilderbrand, S. C., Katwa, P., Lin, S., et al. (2011). Mast cells contribute to altered vascular reactivity and ischemia-reperfusion injury following cerium oxide nanoparticle instillation. Nanotoxicology 5, 531-545. doi: 10.3109/17435390.2010.530004

$\mathrm{Xu}, \mathrm{C}$., and Qu, X. (2014). Cerium oxide nanoparticle: a remarkably versatile rare earth nanomaterial for biological applications. NPG Asia Mater. 6, 1-16. doi: 10.1038/am.2013.88

Yu, L., Scherlag, B. J., Dormer, K., Nguyen, K. T., Pope, C., Fung, K. M., et al. (2010a). Autonomic denervation with magnetic nanoparticles. Circulation 122, 2653-2659. doi: 10.1161/CIRCULATIONAHA.110.940288

Yu, M., Mo, Y., Wan, R., Chien, S., Zhang, X., and Zhang, Q. (2010b). Regulation of plasminogen activator inhibitor-1 expression in endothelial cells with exposure to metal nanoparticles. Toxicol. Lett. 195, 82-89. doi: 10.1016/j.toxlet.2010.02.010

Conflict of Interest Statement: The authors declare that the research was conducted in the absence of any commercial or financial relationships that could be construed as a potential conflict of interest.

Copyright (๑) 2015 Minarchick, Stapleton, Sabolsky and Nurkiewicz. This is an openaccess article distributed under the terms of the Creative Commons Attribution License (CC BY). The use, distribution or reproduction in other forums is permitted, provided the original author(s) or licensor are credited and that the original publication in this journal is cited, in accordance with accepted academic practice. No use, distribution or reproduction is permitted which does not comply with these terms. 